\title{
2595TE BESTUURSVERGADERING,
}

GEHOUDEN 21 FEBRUARI 1885.

Tegenwoordig de heeren Kern (Voorzitter), J. H. de Groot (Penningmeester), van Deventer, Robidé van der Aa, Humme, Schlegel, Bool, Wilken, Niemann en Wijnmalen (Secretaris). Afwezig met kennisgeving de heeren Weitzel en Matthes.

De notulen van het verhandelde in de vorige Vergadering worden gelezen en goedgekeurd.

De Secretaris doet opgave van de sedert de vorige Vergadering ingekomen boekwerken, met voorlezing van de daarbij gevoegde begeleidende missives. Plaatsing der boeken in de bibliotheek, met dankzegging aan de inzenders.

Wordt medegedeeld de ontvangst van:

a. twee missives van Prof. E. Kuhn, Redacteur van het "Literaturblatt für Orientalische Philologie", te Munchen, houdende verzoek om toezending van en dankbetuiging voor de ontvangst van de ontbrekende afleveringen der Bijdragen.

Voor kennisgeving aangenomen.

b. eene missive van de Académie Royale des sciences de Lisbonne, houdende dankbetuiging voor de toezending der afl 3 , deel VIII, van de Bijdragen.

Voor kennisgeving aangenomen.

c. eene missive van Prof. H. Wichmann, te Gotha, houdende verzoek om eenige mededeelingen betreffende het Instituut ten dienste van de voorgenomen uitgave van den "Annuaire géographique de Gotha."

Den Secretaris wordt opgedragen aan dit verzoek te voldaan. 
$d$. een gedrukt schrijven van de familie Blanckenhagen, te 's Gravenhage, berichtende het overlijden van den heer J. J. Blanckenhagen, in den ouderdom van 71 jaren, in leven lid van het Instituut.

Hiervan is bereids aanteekening gehouden.

e. eene missive van het lid H. E. D. Engelhard, houdende bericht van zijn aanstaand vertrek naar Indië, met verzoek de uitgaven van het Instituut, voor hem bestemd, voorloopig naar Batavia te willen opzenden, terwijl zijn gemachtigde, de heer S. W. van der Noordaa, te 's Gravenhage (Raamstraat 53) de contributie te zijner tijd zal aanzuiveren.

Hiervan is mede bereids aanteekening gehouden.

$f$. eene missive van den heer A. Rouffignac, advocaat te SaintGervais les trois-Clochers, Département de la Vienne (France), houdende verzoek hem eenige inlichtingen te verstrekken omtrent de wijze waarop en de voorwaarden, waaronder het lidmaatschap van het Instituut kan worden verkregen.

Den Secretaris wordt opgedragen aan dit verzoek te voldoen.

Betreffende het door Dr. ten Kate voorgenomen anthropologischethnologisch onderzoek van Suriname is van den Directeur van "s Rijks Ethnographisch Museum te Leiden, Dr. L. Serrurier, het volgend schrijven, dd. 23 Januari jl., no. 33, ontvangen:

"Ik veroorloof mij tot $\mathrm{U}$ te komen met een verzoek om ondersteuning van een wetenschappelijken onderzoekingstocht in Suriname. De heer Dr. ten Kate wenscht daarheen te gaan, en hetzij in vereeniging met Prof. Martin, hetzij alleen in de binnenlanden door te dringen.

"Evenzeer als de geologische en botanische kennis onzer WestIndische koloniën tot dusverre verwaarloosd is, en eerst onlangs een poging is ingesteld om tot die kennis te geraken, zoo is ook de ethnologie dier gewesten een "nagenoeg braakliggend terrein. Met uitzondering van den heer van Koolwijk op Aruba heeft nog nimmer een Nederlander zich aldaar met een methodisch anthropologisch onderzoek bezig gehouden. Bezuiden den $5^{\text {en }}$ graad NB. kennen wij de stammen der Indianen en Boschnegers slechts bij name; betrekkelijk de onderlinge verwantschap der Arowakken, Caraïben en 
andere Indianen van Suriname bezitten we slechts oppervlakkige gegevens. Onze naburen zijn ons op dit gebied reeds vooruit. In Britsch-Guyana is het vooral Im Thurn, die de ethnographie der Indianen monographisch behandelt; voorts mag men er wijzen op Barrington Brown en Rob. Schomburgk. In Fransch Guyana kan men de namen noemen van Crevaux, Maurel, Manouvrier en Dally, die voor weinige jaren ons de eerste anthropologische gegevens brachten omtrent de Roucouyennes- en Galibis-Indianen. Het eenige werk dat den staat onzer ethnologische kennis van Suriname aantoont, en dat tevens een eerste bijdrage vormt tot eene monographie der Surinaamsche inboorlingen, is van een vreemdeling; Prins Roland Bonaparte gaf ons laatst het resultaat zijner anthropologische onderzoekingen omtrent de Indianen en Boschnegers van de Amsterdamsche Tentoonstelling. Dit werk is evenwel niet meer dan een eerste grondslag waarop kan en moet worden voortgebouwd.

"Het onderzoek, dat Dr. ten Kate zich voorstelt, is tweeledig:

"10. In de Binnenlanden. De onderzoeker houdt geruimen tijd ı erblijf bij een der in het binnenland wonende stammen, om zoodoende de physische kenmerken, de zeden en gewoonten, enz. van dien stam grondig te leeren kennen, als ook de ethnographische verzameling te Leiden aan te vullen. De ondervinding heeft geleerd dat de ethnologie meer voordeel trekt uit het monographisch bestudeeren van één eukelen stam, dan wanneer men het onderzoek over een aantal stammen verdeelt, en dat de speciale kennis bij één stam opgedaan, ons niet zelden den sleutel geeft van hetgeen ons bij andere stammen onopgehelderd is.

"20. In het huspitaal te Paramaribo. De onderzoeker denkt aldaas anthropologisch materiaal te verzamelen waartoe de omstandigheid, dat zoo verschillende rassen (bruine en zwarte Hindoes, Chineezen, Negers, Mulatten, Zambos en Indianen) de kuststreek bevolken, ruimschoots gelegenheid zal aanbieden.

"Ik koester de hoop dat het Koninklijk Instituut - hoezeer allereerst aan onderzoekingen in Nederlandsch Oost-Indië zijnen steun verleenende - toch iets, hoe weinig ook, voor het anthropologisch ethnologisch onderzoek van Suriname zal willen en kunnen doen, en dat het een gunstig oor zal leenen aan mijn verzoek om een deel der reiskosten van Dr. ten Kate te dragen. Gelijk verzoek richt ik tot de Hollandsche Maatschappij der Wetenschappen te Haarlem en een paar andere instellingen. De bekwaamheden van Dr. ten Kate als wetenschappelijk reiziger zal Uw Bestuur eenigermate kunnen be- 
oordeelen uit diens reisverhaal uit Noord-Amerika, dat ter perse is en waarvan binnen kort een exemplaar aan de boekerij van het Instituut zal wordan aangeboden, gelijk wij thans de eer hebben daarvoor beschikbaar te stellen een exemplaar van No. 1 der "Notices anthropologiques", uitgegeven door 's Rijks Ethnographisch Museum.

"Met de meeste hoogachting, enz."

$\mathrm{Na}$ praeadvies van den Secretaris en eenige gedachtenwisseling wordt besloten den heer Serrurier mede te deelen, dat het Bestuur uit hoofde van den financieëlen toestand van het Instituut en de aanzienlijke uitgaven die het, vooral in het ingetreden dienstjaar, moet bestrijden, zich niet verantwoordt acht eene bijdrage, hoe gering ook, te verleenen voor het voorgenomen onderzoek van Suriname.

Door den Secretaris wordt ter tafel gebracht het hem door Dr. W. N. du Rieu, Bibliothecaris te Leiden, toegezonden afschrift van het Journaal van Brouckhorst, waarvan het oorspronkelijke in de bibliotheek te Karslruhe berust.

$\mathrm{Na}$ eenige beraadslaging wordt besloten het stuk, om bericht en raad, in handen te stellen van de heeren Robidé van der $\mathrm{Aa}$, van Deventer en Schlegel, terwijl de Secretaris machtiging vraagt en erlangt aan den heer du Rieu te berichten, dat over de door hem ten behoeve van gemeld afschrift gedane voorschotten tot een bedrag van $f 40.50$ eene declaratie kan worden ingediend, welke door den Penningmeester zal worden voldaan.

Namens het lid Dr. H. Breitenstein, thans te Weenen, biedt de Secretaris een opstel aan, bevattende eenige mededeelingen over Borneo. $\mathrm{Om}$ bericht en raad in handen gesteld van den heer Wilken.

Door den heer Humme wordt rapport uitgebracht over de in zijne handen gestelde en vanwege het medelid Dr. Horst uit Kroë ontvangen inscriptie.

Onder dankbetuiging aan den Rapporteur wordt besloten het rapport in zijn geheel te doen opnemen in de Bijdragen en 't daartoe in handen te stellen van den Secretaris.

Door den Secretaris worden eenige mededeelingen gedaan omtrent de voorgenomen vertalingen van het koffie-rapport des heeren van Delden-Taërne. Had het Bestuur het recht tot het vertalen van be- 
doeld rapport verleend zonder eenige vergoeding daarvoor te eischen, naar de meening van den Secretaris mocht die vrijgevigheid niet worden uitgestrekt tot de kaartgravuren, waarom dan ook aan den heer M. Nijhoff het voorstel is gedaan om voor het gebruik dier gravuren aan het Instituut eene som van $f 250$ te betalen, welk voorstel door den heer Nijhoff is aangenomen bij schrijven van den 31 Januari jl., zich echter voorbehoudende nader daarop terug te komen. De Secretaris vraagt in deze de meening van het Bestuur.

$\mathrm{Na}$ uitvoerige gedachtenwisseling vereenigt de Vergadering zich eenparig met het gevoelen van den Secretaris en wordt mitsdien zijn aan den heer Nijhoff gedaan voorstel goedgekeurd.

Door den heer Humme wordt, mede namens zijn medelid van Deventer, rapport uitgebracht over de rekening en verantwoording van den Penningmeester over het afgeloopen dienstjaar. Het onderzoek van al de bescheiden heeft de Commissie tot de overtuiging geleid, dat tegen het beheer van den Penningmeester geene bezwaren kunnen worden ingebracht, weswege zij tot goedkeuring daarvan adviseert, onder dankbetuiging voor de zorg der geldmiddelen van het Instituut.

Dienovereenkomstig wordt besloten, terwijl goedgekeurd wordt de leden J. H. P. E. Kniphorst en C. A. M. van Vliet uit te noodigen de rekening van den Penningmeester na te zien en daaromtrent der Algemeene Vergadering te dienen van bericht en raad.

Aan de orde is het opmaken van drietallen, aan de Algemeene Vergadering aan te bieden, voor de verkiezing van drie bestuursleden ter vervanging der niet herkiesbare titularissen, de heeren Weitzel, Niemann en Humme. Uit de stemming blijkt dat zullen worden aanbevolen :

voor de vacature-Weitzel de heeren mr. W. Ridder van Rappard, mr. H. D. Levyssohn Norman en A. Pruys van der Hoeven, allen te 's Gravenhage;

voor de vacature-Niemann de heeren Prof. dr. A. W. T. Juynboll te Delft, H. C. Klinkert te Leiden en J. L. F. Schneider te Delft; voor de vacature-Humme de heeren J. G. F. Riedel te Utrecht, J. H. P. E. Kniphorst en M. T. H. Perelaer te 's Gravenhage.

Door den Secretaris wordt ter tafel gebracht het Verslag, door hem namens het Bestuur in de a.s. Algemeene Vergadering uit te brengen. 
Tegen de algemeene strekking daarvan wordt geene bedenking gemaakt, terwijl, overeenkomstig enkele hem gemaakte opmerkingen, de Secretaris zich bereid verklaart enkele gedeelten van zijn rapport 't zij weg te laten, 't zij te wijzigen, waarna de Voorzitter hem uit naam der Vergadering voor den geleverden arbeid dankzegt.

Tot leden van het Instituut worden benoemd de heeren:

Mr. S. H. Nederburgh, oud-lid van den Raad van Ned. Indië, te 's Gravenhage.

D. Ples, oud-directeur van het depart. van Binnenl. Bestuur, te Haarlem.

K. W. van Gorkom, oud-hoofdinspecteur der cultures, te Baarn.

Jhr. W. van Raders, oud-directeur der burg. openb. werken, directeur der N.-I. stoomvaart-maatschappij, te 's Gravenhage.

Mr. A. Bon Mackay, voorzitter van de Tweede Kamer der StatenGeneraal, te 's Gravenhage.

Mr. A. van Naamen van Eemnes, lid van de Eerste Kamer der Staten-Generaal, te 's Gravenhage.

Mr. W. A. A. J. Bon Schimmelpenninck van der Oye van de Poll, lid van de Eerste Kamer der Staten-Generaal, te 's Gravenhage.

A. Gildemeester, lid van de Tweede Kamer, te Amsterdam.

Mr. B. M. Bahlman, lid van de Tweede Kamer, te Rotterdam,

A. Bon Schimmelpenninck van der Oye van Nyenbeek, oud-lid der Tweede Kamer, te 's Gravenhage.

Mr. J. A. de Vicq, consul der Nederlanden te Djiddah.

Mr. W. B. Greve, hoogleeraar aan de Rijksuniversiteit te Ieiden.

Dr. W. F. G. Suringar, hoogleeaar aan de Rijksuniversiteit te Leiden.

Dr. C. P. Tiele, hoogleeraar aan de Rijksuniversiteit te Leiden.

Mr. A. Beaujon, buitengewoon hoogleeraar, directeur van het Statistisch Instituut, te Amsterdam.

Mr. II. P. G. Quack, directeur der Ned. Bank, te Amsterdam.

W. P. Wolterbeek, te Amsterdam.

Dr. J. P. van der Stok, directeur van het Meteorologisch Observatorium te Batavia, thans te 's Gravenhage.

F. Beijerinck, oud-resident van Soerabaja, te Leiden.

B. van Zutphen, oud-resident van Pontianak, te 's Gravenhage.

J. A. van Hamel, oud-notaris in Indië, thans notaris te Leiden.

A. J. Snouck Hurgronje, oud-notaris te Soerabaja, te 's Gravenhage.

F. C. Valck, gep. O.-I. ambtenaar, te 's Gravenhrge.

Dr. J. C. Filet, oud-geneesheer te Utrecht, 
J. van Gorkom, gep. militair apotheker in Indië, te Haarlem.

P. C. Huijser, oud-tabaksfabriekant, te 's Gravenhage.

M. G. van den Arend, directeur der tabaks-maatschappij Arendsburg, te Rotterdam.

J. M. van der Valk Czn., te 's Gravenhage.

Mr. F. H. Göbel, te 's Gravenhage.

Mr. Jacobus Lion, Rechterlijk Oost-Indisch ambtenaar, met verlof, te 's Gravenhage.

A. N. Clavier, leeraar aan het gymnasium Willem III te Batavia, met verlof te 's Gravenhage.

G. de Wijs, kapitein van den generalen staf O. I. leger, te 's Gravenhage.

J. C. J. Smits, generaal, kommandant te Bronbeek, bij Arnhem.

Van deze keuze zal der Algemeene Vergadering mededeeling worden gedaan.

Niets meer hierna aan de orde zijnde, wordt de Vergadering door den Voorzitter gesloten. 